Trinity University

Digital Commons @ Trinity

Chemistry Faculty Research

Chemistry Department

Spring 2012

\title{
Beyond Cell Penetrating Peptides: Designed Molecular Transporters
}

\author{
P. A. Wender \\ Christina B. Cooley \\ TrinityUniversity, ccooley@trinity.edu \\ E. I. Geihe
}

Follow this and additional works at: https://digitalcommons.trinity.edu/chem_faculty

Part of the Chemistry Commons

\section{Repository Citation}

Wender, P.A., Cooley, C.B., \& Geihe, E.I. (2012). Beyond cell penetrating peptides: Designed molecular transporters. Drug Discovery Today: Technologies, 9(1), e49-e55. doi:10.1016/j.ddtec.2011.07.004

This Post-Print is brought to you for free and open access by the Chemistry Department at Digital Commons @ Trinity. It has been accepted for inclusion in Chemistry Faculty Research by an authorized administrator of Digital Commons @ Trinity. For more information, please contact jcostanz@trinity.edu. 


\title{
Beyond Cell Penetrating Peptides: Designed Molecular Transporters
}

\author{
Paul A. Wender ${ }^{1,}{ }^{,}$, Christina B. Cooley ${ }^{1}$, and Erika I. Geihe ${ }^{1}$ \\ ${ }^{1}$ Departments of Chemistry and Chemical and Systems Biology, Stanford University, Stanford, \\ CA
}

\section{Abstract}

Inspired originally by peptides that traverse biological barriers, research on molecular transporters has since identified the key structural requirements that govern cellular entry, leading to new, significantly more effective and more readily available agents. These new drug delivery systems enable or enhance cellular and tissue uptake, can be targeted, and provide numerous additional advantages of significance in imaging, diagnostics and therapy.

\section{Introduction}

Molecular transporters (MoTrs) are agents that enable or enhance the translocation of drugs or probes across biological barriers [1,2]. We introduced this term in 2000 to consolidate by function (i.e., transport) a then growing list of structures and associated names for agents that affect cellular uptake (e.g., cell penetrating peptides, cell permeating peptides, protein transduction domains, and membrane translocating peptides), as it was clear from our studies that the entry of these agents into cells was not a function of their peptide structure but rather, in the case of the arginine-rich agents, the number and spatial array of their guanidinium groups [3]. Indeed, in a definitive series of structure-function studies starting in the 90s and continuing to the present, we have shown that spaced peptide, peptoid, carbamate, carbonate and dendrimeric scaffolds readily enter cells provided that they are decorated with the appropriate number and arrangement of guanidinium groups [1]. As is true of many lessons learned from natural products, the function of these molecular transporters, in this case translocation into a cell, can thus be mimicked and even improved upon with alternative simplified structures [4]. We and others have further expanded the family of transporters, showing that guanidinium-rich (GR) dendrimers, beta-peptides, foldamers, carbohydrates, PNAs, morpholinos, bicyclic guanidiniums and other non-natural scaffolds can translocate into cells [1]. GR-molecular transporters (GR-MoTrs) have also been shown to cross other biological barriers including skin, blood-brain, ocular, buccal, and membranes of intracellular organelles. Cargoes, which can be either non-covalently associated with or covalently attached to these molecular transporters, include small molecules, imaging agents, metals, peptides, proteins, plasmids, and siRNA. Transport of larger assemblies (e.g., quantum dots, iron particles, vesicles) has also been enhanced by

(C) 2011 Elsevier Ltd. All rights reserved.

"Corresponding author: P.A. Wender (wenderp@stanford.edu).

Other contact information: Address: 337 Campus Drive, Stanford, CA 94305-5080 Phone: (650) 723-0208 Fax: (650) 725-0259. C.B.

Cooley: cnbarnes@stanford.edu; E.I. Geihe: egeihe@stanford.edu. Website: http://www.stanford.edu/dept/chemistry/

Publisher's Disclaimer: This is a PDF file of an unedited manuscript that has been accepted for publication. As a service to our customers we are providing this early version of the manuscript. The manuscript will undergo copyediting, typesetting, and review of the resulting proof before it is published in its final citable form. Please note that during the production process errors may be discovered which could affect the content, and all legal disclaimers that apply to the journal pertain. 
guanidinylation [5]. For cases in which free cargo is required to be released after cell entry, the linker through which the cargo is attached to the transporter can be cleaved by either abiological methods, including light, $\mathrm{pH}$, and heat, or by biological activation including protease, esterase, phosphatase, and redox reactions [6]. Significantly, the transporter-cargo conjugate can be targeted to cells and tissue by "turning off" the oligocation molecular transporter function through attachment to an oligoanion and then "turning on" uptake by cleavage of the attached oligoanion using local cellular or tissue biochemistry $[7,8]$.

Molecular transporter technology has progressed to clinical trails initially for the treatment of psoriasis using cyclosporin-heptaarginine conjugates and subsequently for the treatment of ischemic damage using RACK peptide-transporter conjugates $[9,10]$. Significantly, GRMoTr drug conjugates have also been shown to overcome multidrug resistant cancer in cellular and animal models, even when the drug alone succumbs to resistance [6]. Further therapeutic and research applications of molecular transporters beyond small molecules can be expected as they provide a solution to the singularly most significant problem associated with the clinical use of biologics, namely delivery.

\section{Historical Development of Oligoarginine and Guanidinium-Rich Molecular Transporters}

The field of guanidinium-rich molecular transporters (GR-MoTrs) began with the discovery that the HIV-1 Tat protein crosses cell membranes $[11,12]$, and subsequently that a 9 amino acid region of this protein (residues 49 to 57: RKKRRQRRR) is responsible for cellular uptake [13]. The curiously basic nature of this peptide, its high water solubility, and thus its paradoxical ability to cross the highly nonpolar cellular membrane prompted a detailed series of structure-function investigations by Rothbard and Wender directed at elucidation of the requirements for its entry into cells [3]. N- or C-terminal truncated versions of Tat $49-57$ were found less effective in cellular entry. Similarly, an alanine scan of the Tat 9-mer peptide showed that deletion of any charged residue resulted in a significant decrease in cellular uptake. Given the suggested importance of charge, homooligomers of lysine and of arginine were compared. Oligolysines were ineffective. Strikingly, the arginine homooligomers significantly outperformed not just other polycations (like lysine oligomers), but even the original Tat $49-57$ sequence in uptake (Jurkat cells) $[3,14]$. Of far reaching design significance, subsequent studies demonstrated that the unique ability of arginine oligomers to enter cells was attributable to the number and arrangement of attached guanidinium groups. Methylation of the guanidinium groups resulted in decreased cellular uptake, leading to our suggestion that the positively charged guanidinium groups utilize a bidentate hydrogen bond and electrostatic association to attach to cell surface negatively charged groups (e.g., phosphates, carboxylates and sulfates) thereby initiating cellular entry [15]. A visually stunning experiment involving classical partitioning between water and octanol showed that while fluoresceinated ornithine or arginine homooligomers (both polycationic) partitioned almost exclusively into the water layer, the addition of sodium laurate, a membrane fatty acid surrogate, caused the arginine oligomer (but not the polycationic oligoornithine) to migrate entirely (>95\%) into the octanol layer. Thus the physical properties of this highly polar and water-soluble transporter "morph" from watersoluble to membrane-soluble upon complexation with membrane lipids. The inwardly polarized membrane potential is proposed to then drive this complex into the cell. This mechanism of entry, referred to as adaptive translocation [15], would potentially be operative for small conjugates with a permissively small cross sectional area. As the size of the cargo increases, however, competition if not dominance of various endocytotic mechanisms would arise [16]. In either case, the importance of the guanidinium groups in complexation remains, as they are also implicated in initiating translocation in other proposed mechanisms. Finally, it was shown that uptake is not dependent on peptide 
stereochemistry (notably non-natural (D)-oligomers exhibit higher uptake relative to their (L)-counterparts due to increased protease resistance) further emphasizing the importance of the guanidinium group as the key feature enabling cell entry [3,14]. The realization that the number and arrangement of guanidinium groups are the keys for uptake provided a blueprint for the design of many new peptidic and non-peptidic transporters, opening a field of opportunities for enabling or enhancing drug and probe delivery (Figure 1).

\section{Applications of GR-MoTrs}

As noted above, GR-MoTrs can be used to effect uptake of a long list of probes, drugs and drug leads. Of particular interest to the theme of this publication, GR-MoTrs are effective for the delivery of peptides and proteins. Traditionally considered "undruggable" due to their metabolic instability and general inability to cross biological membranes, many peptides and proteins can be delivered into cells with MoTr technology. Indeed, an impressive example of this capability was the early demonstration that an active $\beta$ galactosidase protein could be delivered across the blood-brain barrier in mice by conjugation to the Tat peptide [17]. More recently oligoarginine-protein fusion constructs have been used to deliver transcription factors to reprogram somatic cells to induced pluripotent stem cells [18]. Among the first peptides delivered with oligoarginine transporters were the RACK octapeptide and Cyclosporine A $[9,10]$. Both have progressed into clinical trials.

In addition to the ability to carry classically undruggable cargoes across biological barriers in cells, animals, and humans, these transporters have been shown to deliver antimicrobials into parasites without killing the host cell [19]. Molecular transporters can also be designed to target intracellular organelles such as the nucleus [1] and mitochondria [20]. Many other groups in addition to those cited herein have creatively contributed to the advancement of the field over the years including Barton, Bogyo, Bräse, Chung, Cooke, Dervan, Dmochowski, Dolphin, Kiso, Kumar, Langel, Martinez, Matile, Mendoza, Moulton, Mueller, Prochiantz, Robbins, Schepartz, Taylor, Torchilin, and Weissledder. Of particular importance with regards to clinical implementation is the ability to access these GR-MoTrs with cost-effective, step-economical synthetic strategies. In this regard, GR-homooligomers offer significant cost and scale advantages in addition to often better performance and tunability relative to the original Tat-9-mer.

\section{Non-peptidic GR-MoTrs}

\section{Linear GR-MoTrs}

The first non-peptidic GR-MoTrs were guanidinium-rich oligopeptoids [3]. While retaining the same 1,4 side chain spacing of the peptide transporters and an amide bond, these peptoid transporters exhibited more flexibility both along the backbone and between the backbone and sidechain. Significantly, they worked better than peptides in comparative uptake studies with Jurkat cells, showing clearly that a conventional peptidic amide bond is not required for cell entry. That more flexible systems would work better is consistent with the dynamics of cell entry rather than an affinity based recognition process for which pre-organization would be important.

Given our finding that the backbone stereochemistry and substitution could be varied, research was next directed at the effect of backbone spacing and composition on uptake $[21,22,23]$. It was found that introduction of aminocaproic acid spacers between arginine groups resulted in GR-MoTrs that outperformed oligomers of arginine alone [21]. $\beta$ peptides, which contain one additional methylene unit between guanidinium containing side chains, showed similar behavior to the a-peptide scaffold: the $\beta$-oligoarginine performed 
well while the $\beta$-oligolysine was less effective [22,24]. An additional and important question was whether the peptide or peptoid backbone could be more dramatically modified. That aminocaproic acid spacers between arginines gave better cellular uptake suggested that this direction would bear fruit. To explore this idea, guanidinium-rich oligocarbamates were synthesized [23]. These oligocarbamates deviated from peptide scaffolds not only in the way in which the backbone is joined (via carbamate linkages), but also in the backbone spacing between guanidinium units (1,6- vs. 1,4-substitution). Guanidinium-rich oligocarbamates were in fact more effective than oligoarginine (an oligocarbamate 9-mer translocated 2.3 times faster into cells than a 9-mer of D-oligoarginine). Together these studies on linear GRMoTrs with modified spacing and backbone composition further underscored the importance of the number and arrangement of guanidinium groups for uptake.

The polyproline scaffold GR-MoTrs developed by Chmielewski and coworkers are an interesting "twist" on the above linear scaffolds [25]. The polyproline scaffold adopts a well-defined left-handed type II helix in polar solvents and can thus be decorated with hydrophobic leucine groups on one helical face and either hydrophilic guanidinium groups or ammonium groups on the other. Fluorescienated versions of these polyproline amphipathic GR-MoTrs were found to penetrate cells effectively, and, as in other studies, the guanidinium-bearing transporters were found to be more effective than their ammoniumbearing counterparts. Notably, the most effective of these guanidinium-bearing transporters outperformed the Tat peptide by almost an order of magnitude. The organization of the hydrophobic and hydrophilic groups along the backbone was found to be important, as transporters with scrambled leucine and guanidinium sequences were not as effective as those organized to form separate hydrophobic and hydrophilic faces. This study demonstrates that effective transporters go beyond flexible, linear scaffolds and that well designed three-dimensional GR-MoTr scaffolds can be effective at cellular uptake.

\section{Branched GR-MoTrs}

In addition to linear scaffolds, dendrimeric and other branched GR-MoTrs have been shown to be effective in promoting cellular entry. The first branched scaffolds, synthesized by the Futaki group in 2002, were based on an amino acid backbone with lysine residues as branch points [26]. As had been shown for the linear systems, uptake was dependent on the guanidinium content (number of arginine residues). The groups of Goodman and Harth as well as our group have reported GR-MoTrs based on dendrimeric scaffolds [27,28,29]. As with the linear scaffolds, uptake was found to be dependent on the number of guanidinium groups, with at least six being required for rapid uptake [27]. Shorter oligomers undergo uptake which, while slow, could still be clinically relevant. In addition to the primary importance of the guanidinium groups, work by our group on dendrimeric scaffolds has shown that the scaffold can also play a role in uptake efficiency [29]. In this work different scaffolds, which had the same number of guanidinium groups but differed in spacing of these groups along the dendrimeric backbone, were analyzed for cellular uptake.

Significantly, the most effective of these dendrimeric GR-MoTrs outperformed nonaarginine, while the least flexible dendrimers did not undergo rapid cellular uptake. Collectively, from a design perspective, these studies indicate that a range of scaffolds, if properly decorated with guanidinium groups, could be used to achieve cell entry.

\section{Other Scaffolds of GR-MoTrs (Guanidinylation of cargo)}

Because of the singular importance of the guanidinium group for cellular uptake and the flexibility that is allowable in the display of these guanidinium moieties, it follows that simply guanidinylating a cargo could be used to enhance its cellular uptake. For example, guanidinylation of oligonucleotides enhances cellular uptake relative to the parent unguanidinylated scaffold. Guanidinylation strategies for oligonucleotides have included 
peptide nucleic acids with insertion of arginine along the backbone [30], guanidinylation at the C5 site of a modified deoxyuridine [31], guanidinylation via attachment of an $\mathrm{N}$-alkyl through the phosphate group of the phosphate backbone [32], and the replacement of the phosphate group with guanidinium groups along the oligonucleotide backbone [33]. All of these varied guanidinylation strategies resulted in systems exhibiting enhanced cellular uptake.

In addition, the guanidinylation of aminoglycosides, including tobramycin and neomycin B, has proven to be an effective strategy for the enhanced cellular uptake of these carbohydrates [34,35]. The resulting guanidinoglycosides exhibited sustained or improved biological function relative to the unmodified scaffold, in one case showing 100 fold greater inhibition of HIV viral replication by guanidinotobramycin and guanidinoneomycin B [36]. These guanidinoglycosides can also act as GR-MoTrs and have been shown to deliver large (>300 kDa) bioactive cargoes into cells [37]. Guanidinylated carbohydrate scaffolds based on inositol and sorbitol have also been shown to readily enter cells $[38,39,40]$. The sheer variety of guanidinylation patterns and strategies and the range of cargoes that have been carried into cells via these strategies highlights the versatility and power of oligoguanidinylation for enabling or enhancing cellular uptake.

\section{Oligomerization-Based Syntheses of GR-MoTrs}

The demonstration that multiple designed linear and branched GR-scaffolds exhibit cell penetrating ability led next to the investigation of new synthetic methods to assemble GRMoTrs that could improve time and step economy and thus lower cost and extend the reach of this technology to additional applications [4]. Inspired by polymer chemistry, an oligomerization strategy offers the potential to assemble multiple guanidinium units in a single operation (Figure 2). This strategy has a number of advantages over traditional methods of transporter assembly such as solid-phase synthesis, which requires 2 steps for each added unit or even solution-phase methods such as segment-doubling, which offers a step count reduction to octaarginine over solid phase synthesis from 17 to 9 steps [41]. Significantly, an oligomerization-based strategy reduces the step count to 2 (oligomerization and deprotection), but perhaps more importantly, it also allows for flexible and rapid access to different length transporters without an increase in step count simply by adjusting the initiator to monomer ratio. For the first time, long as well as short MoTrs can be synthesized in 2 steps. The flexible nature of this assembly allows for the facile exploration of chemical space by dialing in additional functional groups with the synthesis of co-oligomers. While oligomerization-based syntheses give rise to transporters with some polydispersity, the speed of synthesis and thus the speed with which questions can be addressed offer huge advantages in addressing cell entry challenges. In addition, polydispersity could be an advantage in some applications. Significantly, the ability to quickly access new transporters through oligomerization strategies and to interrogate chemical space could greatly facilitate basic research and the determination of lead compounds for clinical development.

In 2008, Kiessling and co-workers reported an oligomerization approach to GR-MoTrs with an alkene backbone using a ring-opening metathesis polymerization (ROMP, Figure 3, a) [42]. By employing a succinimidyl ester-substituted norbornene monomer and an alkene initiator containing a ketone, this strategy allowed for post-polymerization incorporation of both the guanidinium moieties (by displacement of the succinimidyl ester on the side chains) and a model fluorescent cargo (by reaction with the alkene initiator to form an oxime linkage). While guanidinylated oligomers of various lengths were synthesized with this three-step method, initial studies focused on oligomers bearing 10 guanidinium units, which were shown to effectively enter cells using live-cell microscopy. While both the guanidinium moieties and the cargo were appended after the oligomerization process, this 
strategy allows for further diversification by appending appropriate reactive functionality to various monomer side chains, as demonstrated by the ability to construct cell-permeable cooligomers displaying a range of functional groups in addition to the required guanidinium units [43].

In related work by Tew and co-workers, guanidinium-rich oligomers were synthesized by using ROMP with an oxanorbornene scaffold (Figure 3, b) [44]. Unlike the strategy described above, the monomer unit contained a protected guanidinium moiety that was revealed in a simple post-polymerization deprotection step. No cargo (drug or probe) was attached in these studies, but these guanidinylated oligomers were investigated for their transport capability and for antimicrobial activity. Interestingly, they were found to have activity against both gram-positive and gram-negative bacterial strains with low hemolytic activity against human red blood cells [45]. Both of these guanidinium-rich oligomeric scaffolds synthesized by ROMP have slightly different properties than peptide-based systems, namely increased hydrophobicity, which could lead to some differing activity in biological systems relative to the peptide-based GR-MoTrs.

A final example of guanidinium-rich oligomerization was reported in 2009 by a StanfordIBM collaboration utilizing an organocatalytic ring-opening oligomerization process to access a new class of GR-MoTrs based on a carbonate backbone (Figure 3, c) [46]. These oligocarbonate GR-MoTrs can be flexibly and efficiently assembled from a cyclic carbonate monomer containing a protected guanidinium side chain. When a drug or probe is used as the initiator moiety for the oligomerization, cargo attachment results in the same step as transporter synthesis. This new family of oligocarbonate GR-MoTrs was shown to enter cells and deliver cargo analogously to their peptide-based counterparts, using both flow cytometry and bioluminescence assays. A unique feature of the carbonate backbone (especially in contrast to the ROMP-synthesized guanidinium oligomers) is their stability profile; while they exhibit excellent shelf stabilities, they have the novel ability to degrade to non-toxic products after cellular uptake. This distinguishing feature of the carbonate backbone, in addition to the synthetic advantages of transporter assembly by a single step oligomerization strategy, render this scaffold particularly attractive for various biological, imaging, and therapeutic applications.

\section{Concluding Remarks}

In the information-rich age of "omics", one of the major problems - indeed a grand challenge, is understanding biological barriers and how to ferry drugs and probes across those barriers. Nature has provided clues on how this might be done in the form of proteins like Tat. Guanidinium-rich molecular transporters have taken this inspiration to a new level in addressing a range of uptake problems. GR-MoTrs allow for the solubilization of many cargoes while at the same time facilitating passage across nonpolar membranes into cells. After cell entry they allow cargo "payout" at a rate determined by design and are thus effectively "molecular controlled release patches". Oligomerization strategies to synthesize molecular transporters offer an unprecedentedly quick way to test the benefit of this delivery technology. Looking forward, the oligomerization approach to molecular transporters provides the basis for "kits" that would allow rapid cargo conjugation and uptake studies without the need for lengthy syntheses or special laboratories. Significantly, these oligomerization strategies allow facile access to diverse chemical space, on a scale that rivals phage display in terms of the diversity generated when multiple monomers are used. By virtue of their ability to enable or enhance cellular uptake of many cargo types that were previously considered undruggable, molecular transporters open for study, imaging and clinical use, a wider range of compounds including "non-druggable" small molecules, metals, peptides, proteins, nucleic acids, siRNAs and other biologics. 


\section{References}

1. Wender PA, Galliher WC, Goun EA, Jones LR, Pillow TH. The design of guanidinium-rich transporters and their internalization mechanisms. Adv Drug Delivery Reviews. 2008; 60:452-472.

2. Tung CH, Weissleder R. Arginine-containing peptides as delivery vectors. Adv Drug Delivery Reviews. 2003; 55:281-294.

3. Wender PA, Mitchell DJ, Pattabiraman K, Pelkey ET, Steinman L, Rothbard JS. The design, synthesis, and evaluation of molecules that enable or enhance cellular uptake: peptoid molecular transporters. Proc Natl Acad Sci USA. 2000; 97:13003-13008. [PubMed: 11087855]

4. Wender PA, Verma VA, Paxton TJ, Pillow TH. Function oriented synthesis, step economy, and drug design. Acc Chem Res. 2008; 41:40-49. [PubMed: 18159936]

5. Torchilin VP. Tat peptide-mediated intracellular delivery of pharmaceutical nanocarriers. Adv Drug Delivery Reviews. 2008; 60:548-558.

6. Dubikovskaya EA, Thorne SH, Pillow TH, Contag CH, Wender PA. Overcoming multidrug resistance of small-molecule therapeutics through conjugation with releasable octaarginine transporters. Proc Natl Acad Sci. 2008; 105:12128-12133. [PubMed: 18713866]

7. Jiang T, Olson ES, Nguyen QT, Roy M, Jennings PA, Tsien RY. Tumor imaging by means of proteolytic activation of cell-penetrating peptides. 2004; 101:17867-17872.

8. Goun EA, Shinde R, Dehnert KW, Adams-Bond A, Wender PA, Contag CH, Franc BL. Intracellular cargo delivery by an octaarginine transporter adapted to target prostate cancer cells through cell surface protease activation. Bioconjugate Chem. 2006; 17:787-796.

9. Chen L, Wright LR, Chen C-H, Oliver SF, Wender PA, Mochly-Rosen D. Molecular transporters for peptides: delivery of a cardioprotective $\mathrm{EPKC}$ agonist peptide into cells and intact ischemic heart using a transport system, R7. Chem Biol. 2001; 8:1123-1129. [PubMed: 11755391]

10. Rothbard JB, Garlington S, Lin Q, Kirschberg T, Kreider E, McGrane PL, Wender PA, Khavari PA. Conjugation of arginine oligomers to cyclosporin A facilitates topical delivery and inhibition of inflammation. Nat Med. 2000; 6:1253-1257. [PubMed: 11062537]

11. Frankel AD, Pabo CO. Cellular uptake of the Tat protein from human immunodeficiency virus. Cell. 1988; 55:1189-1193. [PubMed: 2849510]

12. Green M, Loewenstein PM. Autonomous functional domains of chemically synthesized human immunodeficiency virus tat trans-activator domain. Cell. 1988; 55:1179-1188. [PubMed: 2849509]

13. Vivés E, Brodin P, Lebleu B. A truncated HIV-1 Tat protein basic domain rapidly translocates through the plasma membrane and accumulates in the cell nucleus. J Biol Chem. 1997; 272:16010-16017. [PubMed: 9188504]

14. Mitchell DJ, Kim DT, Steinman L, Fathman CG, Rothbard JB. Polyarginine enters cells more efficiently than other cationic homopolymers. J Peptide Res. 2000; 56:318-325. [PubMed: 11095185]

15. Rothbard JB, Jessop TC, Lewis RS, Murray BA, Wender PA. Role of membrane potential and hydrogen bonding in the mechanism of translocation of guanidinium-rich peptides into cells. $\mathrm{J} \mathrm{Am}$ Chem Soc. 2004; 126:9506-9607. [PubMed: 15291531]

16. Lee HL, Dubikovskaya EA, Hwang H, Semyonov AN, Wang H, Jones LR, Twieg RJ, Moerner WE, Wender PA. Single-molecule motions of oligoarginine transporter conjugates on the plasma membrane of Chinese hamster ovary cells. J Am Chem Soc. 2008; 130:9364-9370. [PubMed: 18578528]

17. Schwarze SR, Ho A, Vocero-Akbani A, Dowdy SF. In vivo protein transduction: Delivery of a biologically active protein into the mouse. Science. 1999; 285:1569-1572. [PubMed: 10477521]

18. Zhou H, Wu S, Joo JY, Zhu S, Han DW, Lin T, Trauger S, Bien G, Yao S, Zhu Y, Siuzdak G, Schöler HR, Duan L, Ding S. Generation of induced pluripotent stem cells using recombinant proteins. Cell Stem Cell. 2009; 4:381-384. [PubMed: 19398399]

19. Samuel BU, Hearn B, Mack D, Wender P, Rothbard J, Kirisits MJ, Mui E, Wernimont S, Roberts CW, Muench SP, Rice DW, Prigge ST, Law AB, McLeod R. Delivery of antimicrobials into parasites. Proc Natl Acad Sci USA. 2003; 100:14281-14286. [PubMed: 14623959] 
20. Horton KL, Stewart KM, Fonseca SB, Gui Q, Kelley SO. Mitochondria-penetrating peptides. Chem Biol. 2008; 15:375-382. [PubMed: 18420144]

21. Rothbard JB, Krieder E, Vandeusen CL, Wright L, Wiley BL, Wender PA. Arginine-rich molecular transporters for drug delivery: role of backbone spacing in cellular uptake. J Med Chem. 2002; 45:3612-3618. [PubMed: 12166934]

22. Rueping M, Mahajan Y, Sauer M, Seebach D. Cellular uptake studies with Beta-peptides. Chembiochem. 2002; 3:257-259. [PubMed: 11921409]

23. Wender PA, Rothbard JB, Jessop TC, Krieder EL, Wiley BL. Oligocarbamabte molecular transporters: design, synthesis, and biological evaluation of a new class of transporters for drug delivery. J Am Chem Soc. 2002; 124:13382-13383. [PubMed: 12418880]

24. Umezawa N, Gelman MA, Haigis MC, Raines RT, Gellman SH. Translocation of a $\beta$-peptide across cell membranes. J Am Chem Soc. 2002; 124:368-369. [PubMed: 11792194]

25. Fillon YA, Anderson JP, Chmielewski J. Cell penetrating agents based on a polyproline helix scaffold. J Am Chem Soc. 2005; 127:11798-11803. [PubMed: 16104758]

26. Futaki S, Nakase I, Suzuki T, Zhang YJ, Sugiura Y. Translocation of branched-chain arginine peptides through cell membranes: flexibility in the spatial disposition of positive charges in membrane-permeable peptides. Biochemistry. 2002; 41:7925-7930. [PubMed: 12069581]

27. Chung HH, Harms G, Seong CM, Choi BH, Min CH, Taulane JP, Goodman M. Dendritic oligoguanididines as intracellular translocators. Biopolymers- Peptide Science. 2004; 76:83-96. [PubMed: 14997478]

28. Huang K, Voss B, Kumar D, Hamm HE, Harth E. Dendritic molecular transporters provide control of delivery to intracellular compartments. Bioconjug Chem. 2007; 18:403-409. [PubMed: 17284011]

29. Wender PA, Kreider E, Pelkey ET, Rothbard J, VanDeusen CL. Dendritic molecular transporters: synthesis and evaluation of tunable polyguanidino dendrimers that facilitate cellular uptake. Org Lett. 2005; 7:4815-4818. [PubMed: 16235896]

30. Zhou P, Want MM, Du L, Fisher GW, Waggoner A, Ly DH. Novel binding and efficient cellular uptake of guanidine-based peptide nucleic acids (gpna). J Am Chem Soc. 2003; 125:6878-6879. [PubMed: 12783535]

31. Ohmichi T, Kuwahara M, Sasaki N, Hasegawa M, Nishikata T, Sawai H, Sugimoto N. Nucleic acid with guanidinium modification exhibits efficient cellular uptake. Angew Chem Int Ed. 2005; 44:6682-6685.

32. Deglane G, Abes S, Michel T, Prevot P, Vives E, Debart F, Barvik I, Lebleu B, Vasseur JJ. Impact of the guanidinium group on hybridization and cellular uptake of cationic oligonucleotides. Chembiochem. 2006; 7:684-692. [PubMed: 16518865]

33. Dempcy OR, Almarsson O, Bruice TC. Design and synthesis of deoxynucleic guanidine: a polycation analogue of DNA. Proc Natl Acad Sci USA. 1994; 91:7864-7868. [PubMed: 8058725]

34. Luedtke NW, Baker TJ, Goodman M, Tor Y. Guanidinoglycosides: a novel family of RNA ligands. J Am Chem Soc. 2000; 122:12035-12036.

35. Luedtke NW, Carmichael P, Tor Y. Cellular uptake of aminoglycosides, guanidinoglycosides, and poly-arginine. J Am Chem Soc. 2003; 125:12374-12375. [PubMed: 14531657]

36. Baker TJ, Luedtke NW, Tor Y, Goodman M. Synthesis and anti-HIV activity of guanidinoglycosides. J Org Chem. 2000; 65:9054-9058. [PubMed: 11149851]

37. Elson-Schwab L, Garner OB, Schuksz M, Crawford BE, Esko JD, Tor Y. Guanidinylated neomycin delivers large, bioactive cargo into cells through a heparan sulfate-dependent pathway. J Biol Chem. 2007; 282:13585-13591. [PubMed: 17311923]

38. Maiti KK, Jeon OY, Lee WS, Kim DC, Kim KT, Takeuchi S, Futaki S, Chung SK. Design, synthesis, and membrane-translocation studies of inositol-based transporters. Angew Chem Int Ed. 2006; 45:2907-2912.

39. Maiti KK, Jeon OY, Lee WS, Chung SK. Design, synthesis, and delivery properties of novel guanidine-containing molecular transporters built on dimeric inositol scaffolds. Chemistry- Eur J. 2007; 13:762-775.

Drug Discov Today Technol. Author manuscript; available in PMC 2013 April 01. 
40. Maiti KK, Lee WS, Takeuchi T, Watkins C, Fretz M, Kim DC, Futaki S, Jones A, Kim KT, Chung SK. Guanidine-containing molecular transporters: sorbitol-based transporters show high intracellular selectivity toward mitochondria. Angew Chem Int Ed. 2007; 46:5880-5884.

41. Wender PA, Jessop TC, Pattabiraman K, Pelkey ET, VanDeusen CL. An efficient, scalable synthesis of the molecular transporter octaarginine via a segment doubling strategy. Org Lett. 2001; 3:3229-3232. [PubMed: 11594801]

42. Kolonko EM, Kiessling LL. A polymeric domain that promotes cellular internalization. J Am Chem Soc. 2008; 130:5626-5627. [PubMed: 18393495]

43. Kolonko EM, Pontrello JK, Mangold SH, Kiessling LL. General synthetic route to cell-permeable block copolymers via ROMP. J Am Chem Soc. 2009; 131:7327-7333. [PubMed: 19469577]

44. Henning A, Gabriel GJ, Tew GN, Matile S. Stimuli-responsive polyguanidino-oxanorbornene membrane transporters as multicomponent sensors in complex matrices. J Am Chem Soc. 2008; 130:10338-10344. [PubMed: 18624407]

45. Gabriel GJ, Madkour AE, Dabkowski JM, Nelson CF, Nusslein K, Tew GN. Synthetic mimic of antimicrobial peptide with nonmembrane-disrupting antibacterial properties. Biomacromolecules. 2008; 9:2980-2983. [PubMed: 18850741]

46. Cooley CB, Trantow BM, Nederberg F, Kiesewetter MK, Hedrick JL, Waymouth RM, Wender PA. Oligocarbonate molecular transporters: Oligomerization-based syntheses and cell-penetrating studies. J Am Chem Soc. 2009; 131:16401-16403. [PubMed: 19860416] 


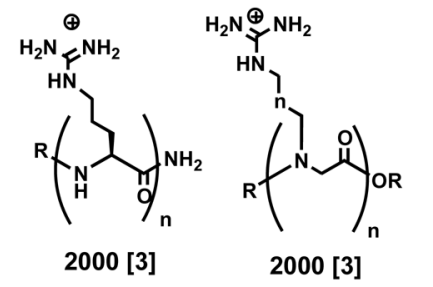<smiles>[R][R]([R])[R][R]([R])[R]</smiles>

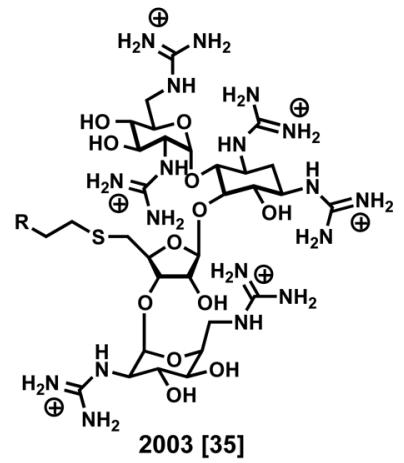

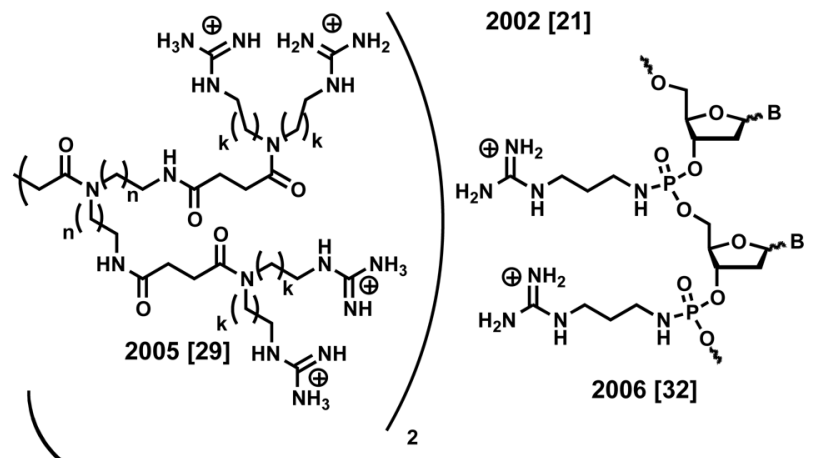

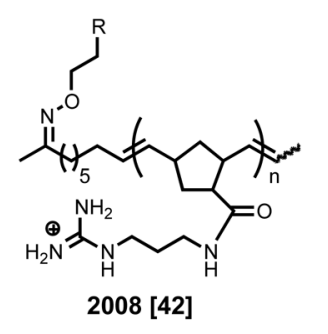<smiles>[2H]CCOC(=O)OCC(CC)OCCNC(=N)N</smiles>

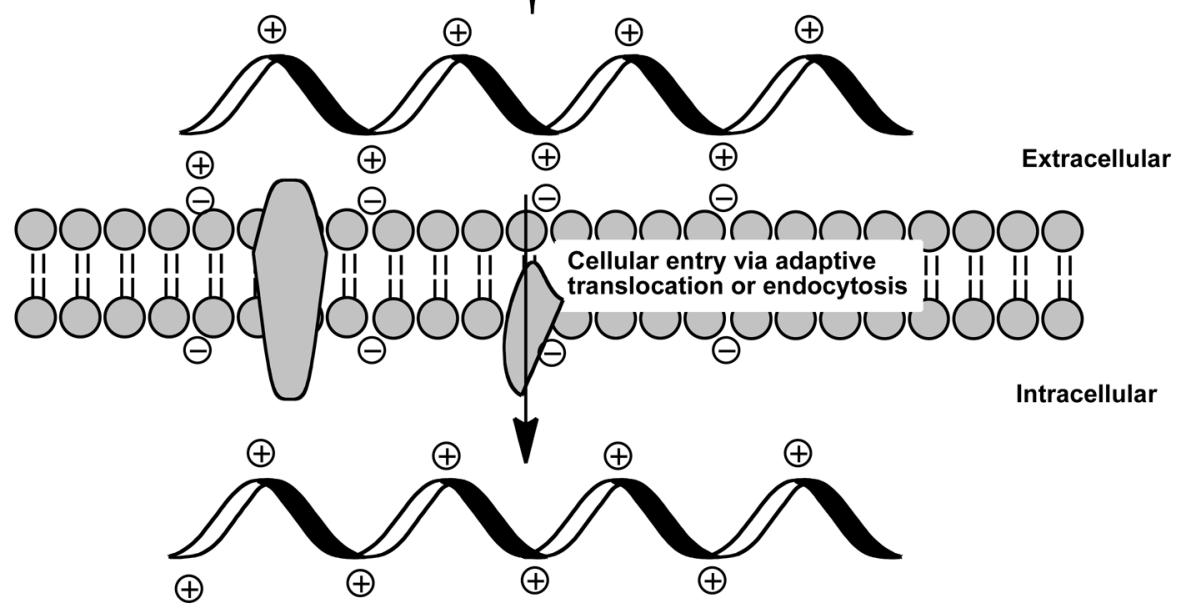

Figure 1.

Representative examples of GR-MoTrs. 
a)

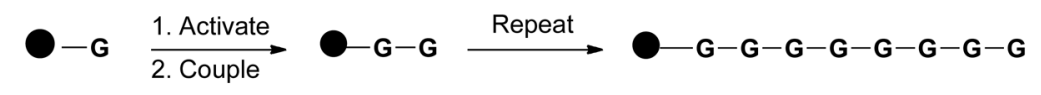

b)

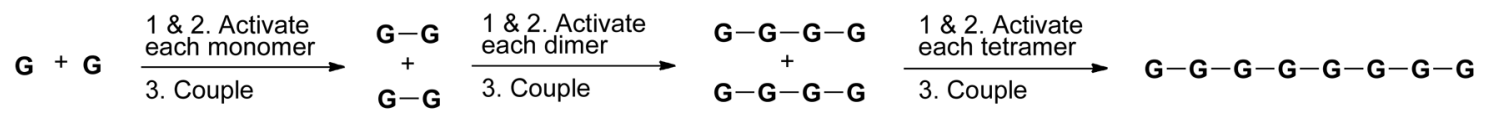

c)

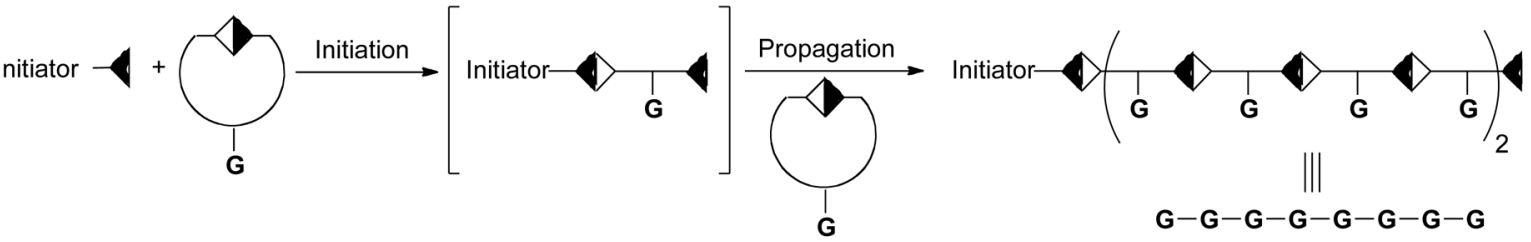

d)

\begin{tabular}{|c|c|c|}
\hline Synthetic Method & $\begin{array}{c}\text { Step Count for } \\
\mathbf{8} \text { Guanidiniums }\end{array}$ & $\begin{array}{c}\text { Step Count for } \\
\mathbf{5 0} \text { Guanidiniums }\end{array}$ \\
\hline Solid Phase & 16 & 100 \\
\hline Segment Doubling* & 9 & $\sim 18$ \\
\hline Oligomerization & 1 & 1 \\
\hline
\end{tabular}

*Not all oligomer lengths are accessible by the segment doubling approach

Figure 2.

Schematic of synthetic approaches to GR-MoTrs and step count considerations. a) solidphase synthesis, b) segment-doubling approach for homooligomers [41], c) oligomerization approach [46], d) table of step count comparison for the syntheses of different length oligomeric GR-MoTrs, $\mathrm{G}=$ guanidinium containing unit. 
a)

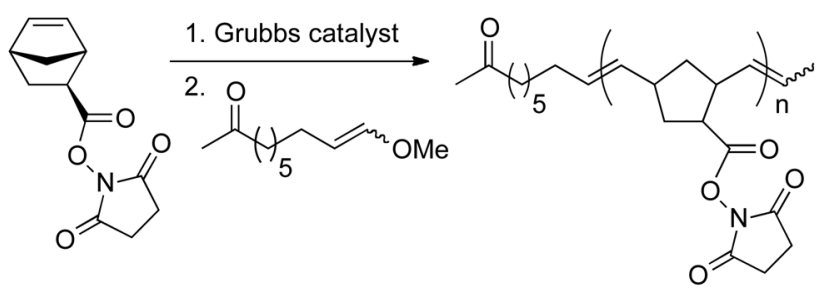<smiles>COCCONC(=O)NCCCN</smiles>

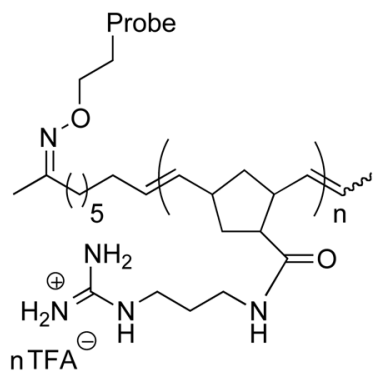

b)

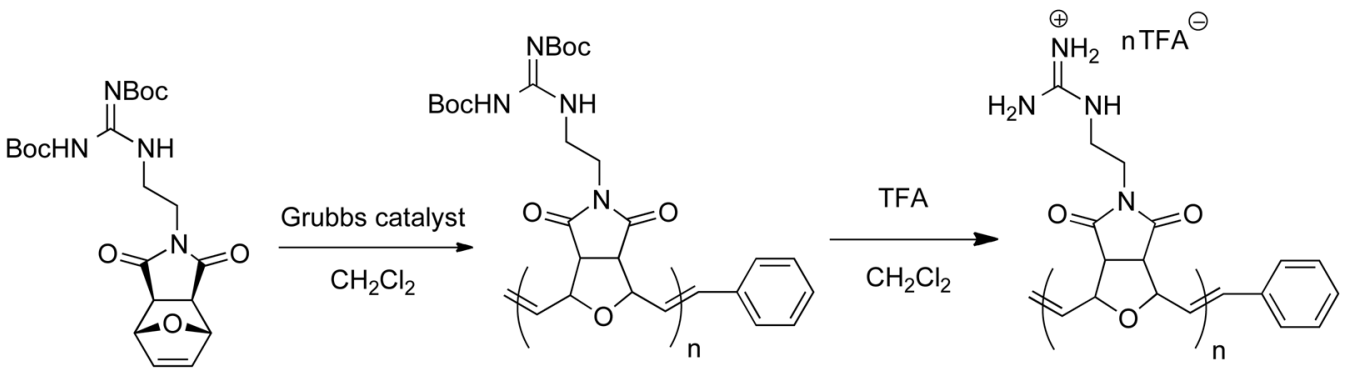

c)

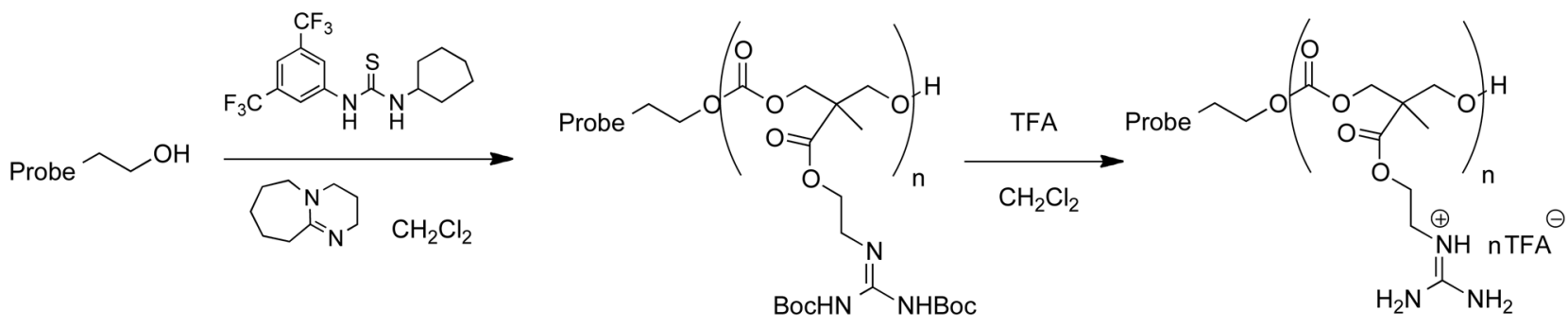

Figure 3.

Syntheses and structures of oligomerization-based GR-MoTrs. a),b) ROMP oligomerizations [42, 44], c) organocatalytic carbonate oligomerization [46]. 